\title{
INFLUÊNCIA DA MICROESTRUTURA DE UM AÇO SAE 1095 NA RESISTENNCIA AO DESGASTE ABRASIVO
}

\section{INFLUENCE OF THE MICROSTRUCTURE OF THE STEEL SAE 1095 IN THE ABRASIVE WEAR RESISTANCE}

\author{
Prof. Dr. Alessandro Fraga Farah - alessandro.farah@fatec.sp.gov.br \\ Profa. Mestra Solange Pereira dos Santos Farah - solangepsfarah@uol.com.br \\ Profa. Mestra Márcia Aparecida Gomes - marcia.gomes@usp.br \\ Faculdade de Tecnologia (FATEC) - Sertãozinho - SP - Brasil \\ Vinicius Henrique dos Santos - vinicius.saantos01@gmail.com \\ Anderson Luís de Oliveira - anderson.olitecno@gmail.com \\ Tecnólogos em Mecânica: processos de soldagem \\ Faculdade de Tecnologia (FATEC) - Sertãozinho - SP - Brasil
}

\section{RESUMO}

O objetivo deste trabalho foi estudar um aço SAE 1095, fundido, com diferentes tratamentos térmicos para verificar a influência da microestrutura na resistência ao desgaste abrasivo. Os corpos de prova foram submetidos a tratamentos térmicos, ensaios de dureza e ensaios de desgaste abrasivo e caracterização microestrutural. Foram realizados tratamentos térmicos de normalização a $900^{\circ} \mathrm{C}$ seguido de resfriamento ao ar; têmpera partindo de $900^{\circ} \mathrm{C}$ de austenitização e resfriado em água; têmpera partindo de $800^{\circ} \mathrm{C}$ de austenitização e resfriado em água; revenimento em duas temperaturas diferentes sendo a primeira a $205^{\circ} \mathrm{C}$ e a segunda a $420^{\circ} \mathrm{C}$, sendo o resfriamento realizado ao ar. Posteriormente, as medidas de dureza foram efetuadas, e em seguida foram realizados os ensaios de desgaste abrasivo do tipo roda de borracha (ASTM G65). A caracterização microestrutural foi feita por microscopia ótica, utilizando diferentes ataques químicos para melhor identificação das fases. Os resultados obtidos neste trabalho mostraram um material com boa resistência ao desgaste abrasivo, dependendo da sua condição microestrutural.

Palavras-chave: SAE 1095. Resistência ao Desgaste. Tratamentos térmicos.

\begin{abstract}
The objective of this work was to study a SAE 1095 steel, cast, with different thermal treatments to verify the influence of the microstructure on the resistance to abrasive wear. The specimens were subjected to thermal treatments, hardness tests and abrasive wear tests and microstructural characterization. Thermal treatments of normalization were carried out at $900^{\circ} \mathrm{C}$ followed by air cooling; quenching from $900^{\circ} \mathrm{C}$ austenitization and cooled in water; quenching starting at $800^{\circ} \mathrm{C}$ from austenitization and cooled in water; tempering at two different temperatures, the first being at $205^{\circ} \mathrm{C}$ and the second at $420^{\circ} \mathrm{C}$, with cooling to air. Subsequently, the hardness measurements were performed, and then the rubber wheel type abrasive wear tests (ASTM G65) were performed. The microstructural characterization was made by optical microscopy, using different chemical attacks to better identify the phases.
\end{abstract}


depending on its microstructural condition.

Keywords: SAE 1095. Wear resistance. Heat Treatments.

\section{DOI:}

\section{INTRODUÇÃO}

Os aços de acordo com Marques, Modenesi e Bracarense (2011) são as ligas ferrosas mais utilizadas pelo homem dentre as ligas metálicas, pelo fato de ser de fácil processamento e obtenção, que podem ser ligar-se a elementos metálicos ou não metálicos.

Sendo assim um dos mais utilizados nas indústrias é o aço-carbono que são aços onde o carbono é seu elemento químico principal, é um aço de fácil obtenção e processamento como já citados, além de serem de baixo custo, e possuírem uma vasta gama de propriedades para seu uso, são aços tratáveis termicamente e podem ser ligados a outros elementos químicos como o $\mathrm{V}, \mathrm{W}, \mathrm{Nb}, \mathrm{Cr}, \mathrm{Ni}$, Mo, por exemplo, para melhoria de suas propriedades mecânicas, resistência ao desgaste e resistência a corrosão.

Entretanto o aço utilizado para este presente trabalho é um aço-carbono o SAE 1095, sendo um aço de alto teor em carbono, que possuem propriedades de alta dureza e resistência ao desgaste.

Dessa forma, o desgaste de componentes e equipamentos industriais dentre outros setores econômicos, representa grande parte de depreciação de capital e fonte de despesas de manutenção e reposição de componentes mecânicos, pois o fenômeno de desgaste é impossível de se evitar, mas é possível minimizá-lo se a escolha for correta do material, das aplicações de revestimentos e dos tratamentos térmicos.

O desgaste é um fenômeno superficial que causa a perda de massa, degradação e deteorização do material, e que em inúmeras situações pode causar a falha de um componente ou equipamento, sendo $50 \%$ da causa de falhas o desgaste abrasivo. Então o desgaste é mais severo em condições de serviço, devido à presença de partículas abrasivas de areia ou pó metálico presentes. Além disso, outros fatores devem ser levados em consideração sobre a resistência ao desgaste, como a presença de carbonetos na composição química da liga de material utilizado, a dureza, tenacidade, e microestrutura. Para a resistência ao desgaste o 


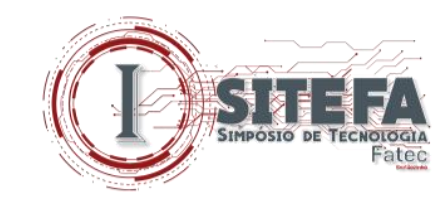

material deve ter uma composição química que se associe com o tratamento térmico para obter as propriedades de alta dureza e resistência à abrasão.

O presente estudo inicia-se por uma revisão bibliográfica referente aos aços, aos tratamentos térmicos, aos sistemas tribológicos do desgaste, com intuito de caracterizar o aço SAE 1095 para a resistência ao desgaste.

\section{AÇOS}

Os aços, segundo Marques, Modenesi e Bracarense (2011), são as ligas mais utilizadas pelo homem, pela facilidade de refiná-los e produzi-los em grande variedade, por serem de baixo custo e terem uma vasta gama de propriedades físicas e mecânicas que podem ser obtidas por adição de elementos de ligas como: $\mathrm{Cr}$, Mo, Ni, por exemplo, ou pelo controle de tratamentos térmicos.

De acordo com Chiaverini (2008), os aços contem geralmente de 0,008 a 2,11\% de carbono em sua liga, além de elementos residuais gerados durante o processo de sua fabricação.

\subsection{Aços comuns ou ao carbono}

Os aços ao carbono são ligas de ferro-carbono que geralmente possuem pequenas quantidades dos elementos $\mathrm{C}, \mathrm{Si}, \mathrm{Mn}, \mathrm{Cu}, \mathrm{S}$ e $\mathrm{P}$, outros elementos existem apenas em quantidades residuais, além de que outros elementos podem ser adicionados intencionalmente para melhoria de suas propriedades. Neste aço, o carbono é o elemento principal que influencia em suas propriedades, por exemplo, quando se tem alto teor de carbono tem-se aumento das propriedades de resistência mecânica e a dureza porem tem-se a diminuição da tenacidade e ductilidade, ou seja, estas propriedades são inversamente proporcionais. Segundo CHIAVERINI (2008), os aços carbono se classificam em função do teor de carbono, sendo:

1. Baixo teor de carbono: contem até no máximo $0,30 \%$ de $\mathrm{C}$ na liga; São aços de boa soldabilidade são de fácil usinagem, possui propriedades de baixa dureza, e alta ductilidade e tenacidade, e possuem baixa resistência mecânica, são aplicáveis em: chapas automobilísticas, fabricação de tubos, folhas de flandres entre outros, visto que estes aços não são tratáveis termicamente 
2. Médio teor de carbono: de 0,30 a $0,60 \%$ de C; são de maiores resistências mecânica e dureza quando comparados aos de baixo teor em carbono, porém sua ductilidade e tenacidade são menores, são relativamente tratáveis termicamente por ter quantidade de teor em carbono suficiente para isso, e são aplicáveis em: equipamentos rodoviários, engrenagens entre outras peças que necessitem de boa resistência mecânica e ao desgaste.

3. Alto teor de carbono: de 0,60 a 1,00 \% de C. São de maiores resistências mecânica e dureza, porem de menor ductilidade e tenacidade, são bem temperáveis e são utilizados nas condições temperadas e revenidas em suas aplicações bem como: folhas de serrote, martelos e facas, ou seja, aplicações que são necessário bom gume cortante, geralmente associado à alta dureza e resistência ao desgaste.

\subsection{Aço SAE 1095}

$\mathrm{O}$ aço SAE 1095, é um aço de alto teor de carbono, teoricamente com 0,95\% de $\mathrm{C}$ em sua liga, e que reúne um bom conjunto de propriedades mecânicas dentre as quais podemos destacar temos a alta dureza e resistência mecânica e resistência a abrasão.

Este aço possui características de alta temperabilidade, má soldabilidade, e usinabilidade razoável. A Tabela 1 mostra a composição química deste aço e a Tabela 2 suas propriedades resumidamente em condições variadas.

Tabela 1- Composição química em peso (\%) aço SAE 1095.

\begin{tabular}{cccc}
\hline $\mathrm{C}$ & $\mathrm{Mn}$ & $\mathrm{P}$ & $\mathrm{S}$ \\
\hline 0,9 a 1,03 & 0,3 a 0,50 & 0,04 & 0,05 \\
\hline
\end{tabular}

Tabela 2 - Propriedades do aço SAE 1095

\begin{tabular}{ccccc}
\hline Aço SAE 1095 & $\begin{array}{c}\text { Temperatura de } \\
\text { Austenitização }\left({ }^{\circ} \mathrm{C}\right)\end{array}$ & $\begin{array}{c}\text { Resistência à } \\
\text { Tração }(\mathrm{MPa})\end{array}$ & $\begin{array}{c}\text { Limite de Escoamento } \\
(\mathrm{MPa})\end{array}$ & $\begin{array}{c}\text { Dureza } \\
(\mathrm{HB})\end{array}$ \\
\hline Laminado & - & 965 & 570 & 293 \\
Normalizado & 900 & 1015 & 505 & 293 \\
Recozido & 790 & 655 & 380 & 192 \\
\hline
\end{tabular}

Fonte: Manual Aços Gerdau (2017) 


\subsection{Tratamentos térmicos}

Os tratamentos térmicos são um conjunto de operações em que envolvem um ciclo de aquecimento e resfriamento, sob condições controladas de tempo, temperatura e velocidade de resfriamento, tendo como objetivo alterar as propriedades físicas e mecânicas dos aços, sem mudar a sua composição química e forma física.

Entretanto a alguns parâmetros devem ser levados em consideração na prática dos tratamentos térmicos como a atmosfera do forno, a temperatura e o tempo de permanência, e a velocidade de resfriamento.

A temperatura depende do tipo de aço, o tempo de permanência na temperatura depende da geometria da peça.

O resfriamento é o fator importante, pois juntamente com a composição química definirá a estrutura final do aço, podendo ser realizadas em água, ao ar, em óleo, dentro do forno, ou em soluções aquosas (polímeros ou salmoura).

Sendo assim existem os tratamentos térmicos de recozimento, têmpera, revenimento, martêmpera, austêmpera e normalização (CHIAVERINI, 2003). Onde a normalização é um tratamento que tem como objetivo refinar os grãos dos aços melhorando uniformemente sua estrutura, sendo utilizado após as peças de aço fundidos depois de laminadas ou forjadas, e antes dos tratamentos de têmpera e revenimento, melhorando as propriedades mecânicas do aço tais como; a redução de empenamentos, facilita a solução de carbonetos e elementos de ligas. $\mathrm{O}$ tratamento térmico de têmpera consiste em resfriamento rápido de um aço à partir das temperaturas de austenitização e o objetivo deste tratamento é aumentar à dureza, a resistência a tração e ao desgaste, com a obtenção da microestrutura final a "martensita".

Nos aços, independente da porcentagem de carbono, a sua microestrutura em temperaturas altas é composta da fase austenita, apresentando estrutura CFC, que quando resfriada pode resultar na formação de outras fases dependendo da velocidade de resfriamento. A representação na Figura 1 mostra a transformação da austenita em outros microstituintes. 
Figura 1 - Transformação da austenita em outros microstituintes.

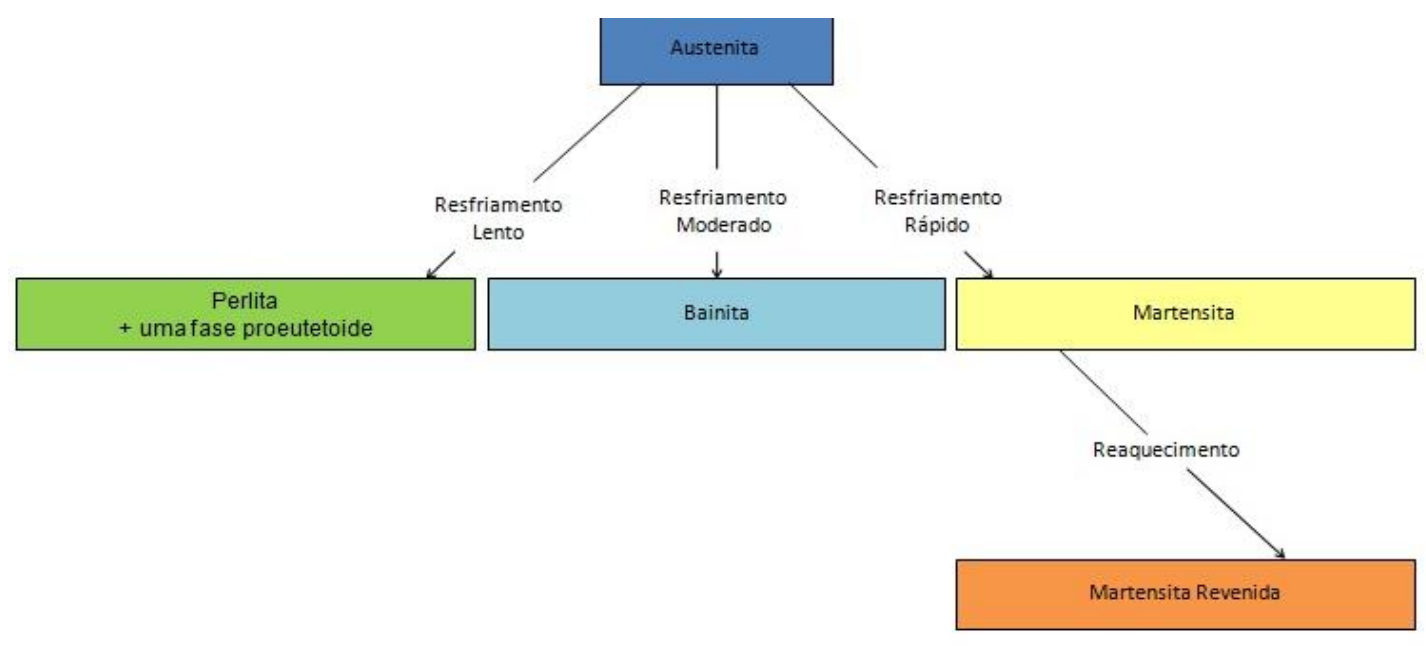

Fonte: Callister (2015, p. 322)

A perlita é composta das fases ferrita $(\alpha)+$ cementita $\left(\mathrm{Fe}_{3} \mathrm{C}\right)$, formando uma estrutura com camadas alternadas dos mesmos. A bainita é formada pelas mesmas fases que a perlita, porem na bainita têm-se uma estrutura com matriz de ferrita e partículas de cementita, sendo muito fina e em forma de agulhas. A martensita forma-se com o resfriamento brusco e rápido, impedindo forma outra estrutura, formado por solução de supersaturada de carbono no ferro, formando então uma microestrutura monofásica fora do equilíbrio, em forma de ripas ou agulhas, e de alta dureza. A martensita revenida se forma abaixo da temperatura eutetóide onde as fases $\alpha$ e $\mathrm{Fe}_{3} \mathrm{C}$ se precipitam e causa diminuição da dureza e aumento de tenacidade dos aços temperados (CALLISTER, 2015).

\subsection{Definições do Desgaste}

Pode-se definir o desgaste como um dano a uma superfície solida, envolvendo a perda indesejável de material por ação mecânica, que pode agir de forma combinada ao corte, a deformação, a fragmentação superficial ou atrito entre superfícies em movimento relativo em contato com outra, ou com outra substancia de contato ou sem contato (GREGOLIN, 1990).

O desgaste pode ocorrer de forma combinada a outros fenômenos de degradação como, o impacto, a corrosão, a fadiga, e a fluência (GREGOLIN, 1990). 
O desgaste tem grande importância no que se refere à vida útil e funcionalidade de componentes ou equipamentos, por inviabilizar a funcionalidade dos mesmos, sendo considerado um fato inevitável (CASTRO, 2010).

Então devido ao grande prejuízo causado pelo desgaste, Noble (1985 apud FARAH 1997, p.13), indica três áreas que levam a redução do custo sendo:

Primeiro, aumenta-se a vida útil dos componentes, pois assim diminui os custos de reposição do mesmo, segundo evita-se a parada de componente e assim limita-se a perda de produção, e terceiro reduz-se os custos de investimentos por meio de aumento da vida útil dos maquinários.

Existem diversos fatores que levam ao desgaste, de acordo com Farah (1997), sendo relacionados a fatores tribológicos, podendo mencionar: os materiais envolvidos, lubrificação, temperatura, carga aplicada, velocidade de movimento, e o mais importante o meio ambiente, onde cada um desses fatores tem um efeito significativo no desgaste.

Com a diversidade de fatores que envolvem o desgaste há classificações para facilitar o estudo deste fenômeno sendo as principais: desgaste abrasivo, desgaste erosivo, desgaste corrosivo, e desgaste por fadiga superficial, além de outros fatores como a cavitação, o fretting e a erosão que agem em conjunto de outros tipos de desgaste.

Sendo assim Farah (1997), classifica em sua publicação os tipos de desgaste mais encontrados frequentemente nas indústrias, como: o desgaste abrasivo, desgaste por deslizamento, desgaste erosivo e desgaste por fretting. Sendo o desgaste abrasivo responsável por mais da metade das perdas.

\subsection{Desgaste Abrasivo}

Este tipo de desgaste pode ser caracterizado pelo tipo de contato, podendo ser classificado em dois tipos, sendo um por abrasão em dois corpos e outro por abrasão em três corpos, onde as partículas abrasivas podem prover de diferentes formas de avarias como: o microssulcamento, microcorte, microfadiga, e microtrinca. Entretanto o desgaste abrasivo pode ocorrer com a presença de partículas duras abrasivas entre duas superfícies de contato compondo o tribossistema onde uma superfície atua sobre a outra, podendo ser por: areias, sujeiras, partículas metálicas por exemplo, estas partículas podem estar na superfície ou incrustadas em uma ou nas duas superfícies de contato em movimento. (FARAH, 1997). 
Portanto para a diminuição do desgaste de forma geral, deve-se levar em consideração os vários fatores como: a composição química do material, as variáveis metalúrgicas, as condições de serviços, meio ambiente, temperatura, lubrificação, formas de desgaste, etc.

De fato, com o conhecimento dos fatores citados, é possível escolher o material correto para suas aplicações, após a escolha de material pode-se ainda obter aumento de resistência ao desgaste por aplicação de revestimentos duros sobre a superfície do material, e/ou aplicação de tratamentos térmicos convencionais como a têmpera e revenimento, por exemplo, todos afins de reduzir os prejuízos causados pelo desgaste (FARAH, 1997).

\section{MATERIAIS E MÉTODOS}

Nesta seção serão apresentados os materiais e equipamentos utilizados para caracterização do aço estudado, o SAE 1095. A Figura 2 mostra o fluxograma da metodologia para a caracterização do aço $S A E 1095$.

Figura 2 - Fluxograma para metodologia aplicada

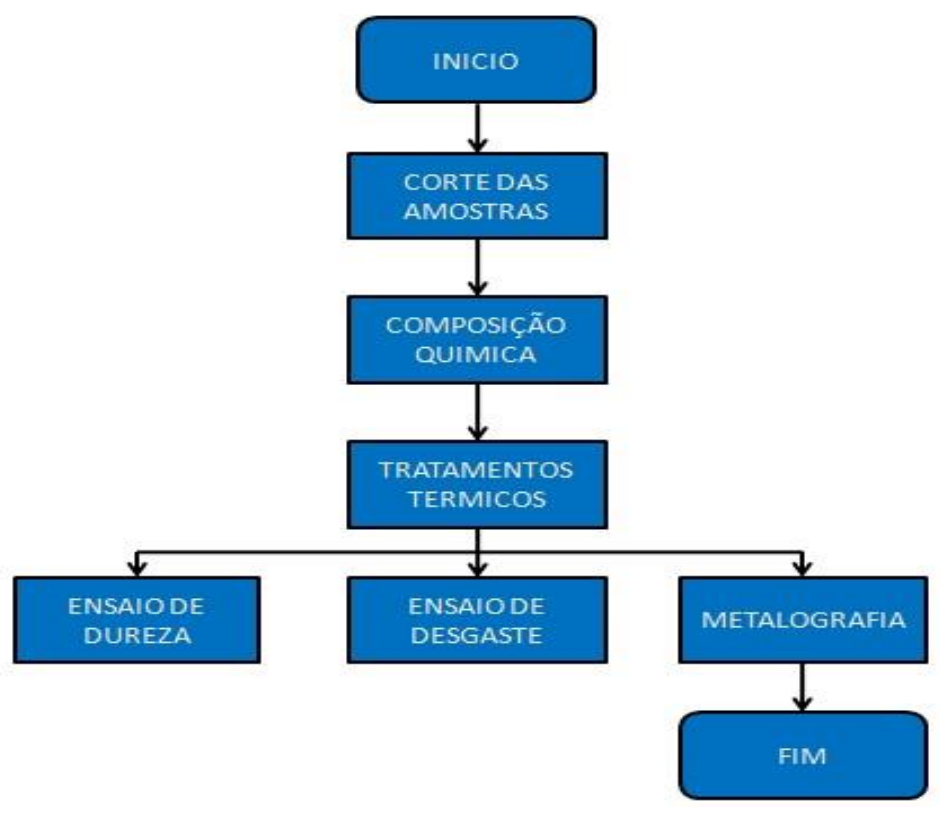

Fonte: os autores 
As amostras do aço fundido SAE 1095 na condição recozida, foram cortados e confeccionados nas dimensões: $55 \mathrm{~mm}$ x $26 \mathrm{~mm}$ x $11 \mathrm{~mm}$. Após o corte das amostras, foi realizado a análise química do material no espectrômetro no laboratório de microscopia da Fatec Sertãozinho. Com a finalidade de se obter estruturas resistentes ao desgaste, os tratamentos térmicos e as temperaturas foram definidos de acordo com a Tabela 3.

Tabela 3 - Temperaturas de austenitização nas amostras.

\begin{tabular}{cccc}
\hline Tratamentos Térmicos & \multicolumn{2}{c}{ Temperatura $\left({ }^{\circ} \mathrm{C}\right)$} & Meio de Resfriamento \\
\hline Normalização & 900 & - & $\mathrm{Ar}$ \\
Têmpera & 800 & 900 & Água \\
Revenimento & 205 & 420 & $\mathrm{Ar}$ \\
\hline
\end{tabular}

Fonte: os autores

Os ensaios de dureza foram efetuados num durômetro analógico tipo Rockwell C.

Os ensaios de desgaste foram realizados no equipamento do tipo de roda de borracha utilizando areia seca como abrasivo, padronizados pela norma ASTM G65-04.

As amostras para análise metalográfica foram extraídas dos corpos de provas após os tratamentos térmicos efetuados. O ataque químico foi feito com Nital $2 \%$ e Picrato de Sódio.

\section{RESULTADOS E DISCUSSÃO}

A Tabela 4 mostra a composição química encontrada no material em estudo.

Tabela 4 - Composição química do aço SAE 1095 em peso (\%).

\begin{tabular}{cccccc}
\hline $\mathbf{C}$ & $\mathbf{M n}$ & $\mathbf{S i}$ & $\mathbf{P}$ & $\mathbf{S}$ & $\mathbf{F e}$ \\
\hline 1,11 & 0,78 & 0,52 & 0,0085 & 0,0094 & 97,56 \\
\hline
\end{tabular}

Fonte: os autores

Esta composição química é típica de um aço classificado como SAE 1095.

Após os tratamentos térmicos foram tiradas cinco medidas em cada amostra, feito isso foi determinada a média aritmética destas medidas, em seguida foi feito o cálculo do desvio padrão dos mesmos. A Tabela 5 mostra os resultados obtidos. 


\begin{tabular}{llll}
\hline Amost & Condição & Dureza & D.P \\
\hline CP01 & Recozido & 25 & 1,10 \\
CP02 & Normalizado & 33 & 0,45 \\
CP03 & Temp. $\left(800^{\circ} \mathrm{C}\right)+\operatorname{Rev} .\left(205^{\circ} \mathrm{C}\right)$ & 61 & 1,30 \\
CP04 & Temp. $\left(800^{\circ} \mathrm{C}\right)+\operatorname{Rev} .\left(420^{\circ} \mathrm{C}\right)$ & 47 & 1,52 \\
CP05 & Temp. $\left(900^{\circ} \mathrm{C}\right)+\operatorname{Rev} .\left(205^{\circ} \mathrm{C}\right)$ & 60 & 2,73 \\
CP06 & Temp. $\left(900^{\circ} \mathrm{C}\right)+\operatorname{Rev} .\left(420^{\circ} \mathrm{C}\right)$ & 48 & 0,87 \\
\hline
\end{tabular}

Fonte: os autores

Os valores obtidos da perda de massa dos corpos de provas ensaiados por abrasômetro tipo roda de borracha, foram realizados para avaliar qual meio de tratamento térmico é mais eficaz em relação à resistência ao desgaste abrasivo.

O Gráfico 1 mostra a perda de massa em (mg), em função do tempo (min), durante o ensaio de desgaste abrasivo do tipo roda de borracha com areia seca.

Gráfico 1 - Perda de Massa (mg) em relação ao tempo (min).

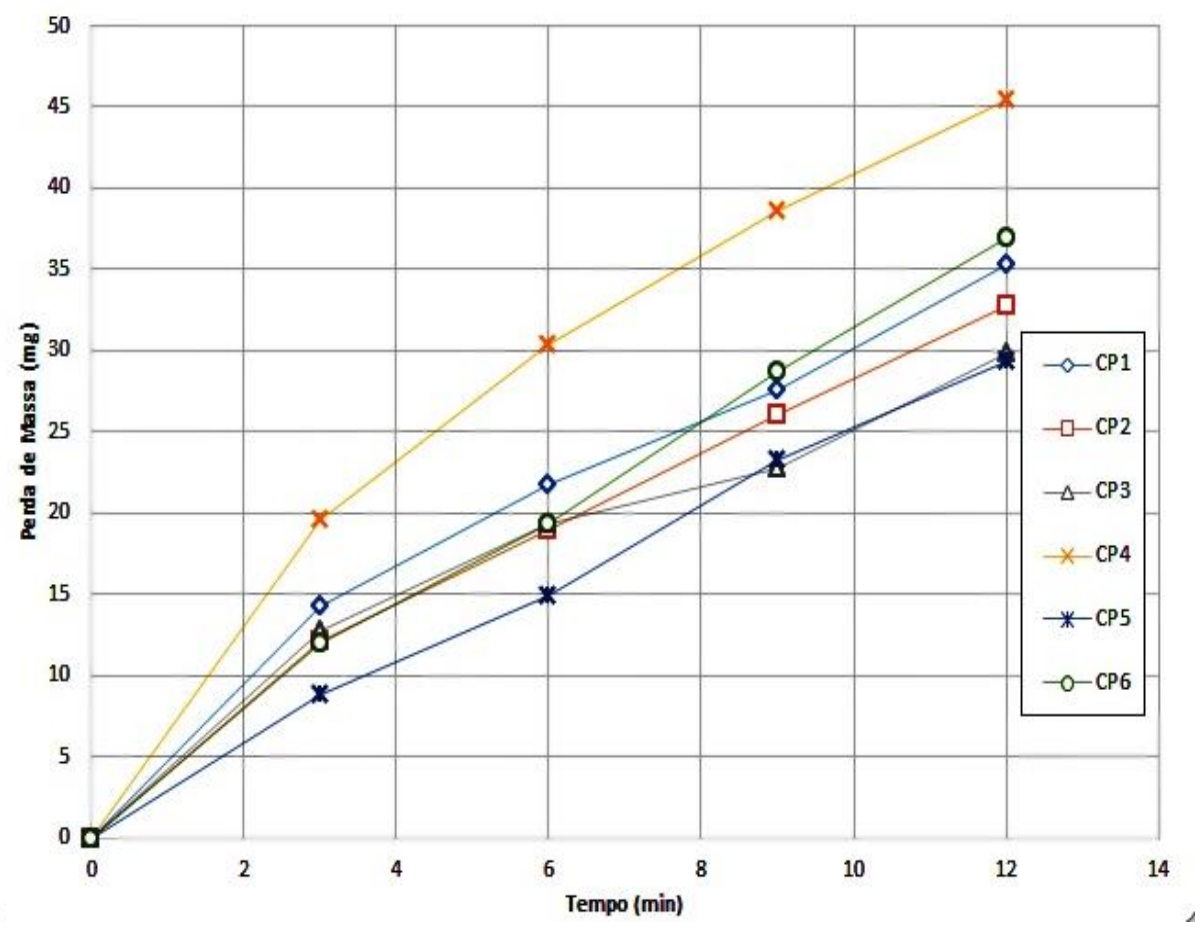

Fonte: os autores

Os resultados da perda de massa nos corpos de provas do aço SAE 1095 nas condições mostram que se obteve melhor resistência ao desgaste o CP03 e o CP05, sendo que o primeiro 


\section{SIIEFA}

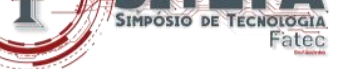

estava na condição temperada a $800^{\circ} \mathrm{C}$ e revenida a $205^{\circ} \mathrm{C}$, e o segundo que melhor resistiu a abrasão foi o $\mathrm{CP} 5$ temperado a $900^{\circ} \mathrm{C}$ e revenido a $205^{\circ} \mathrm{C}$, o terceiro que apresentou melhor resistência ao desgaste foi CP02 com tratamento térmico de normalização.

A resistência ao desgaste depende de vários fatores e um deles é a microestrutura e sendo assim foram realizadas análises micrográficas. As figuras a seguir mostram as microestruturas obtidas após realização dos tratamentos térmicos em cada corpo de prova. A Figura 4 o CP01 mostra a estrutura formada do aço SAE 1095 no seu estado recozido, onde o mesmo revelou grãos grosseiros compostos de perlita, com contorno de grãos de cementita.

Figura 4 - CP01 Recozido. Ataque químico: (a) NItal 2\% (b) Picrato de Sódio.
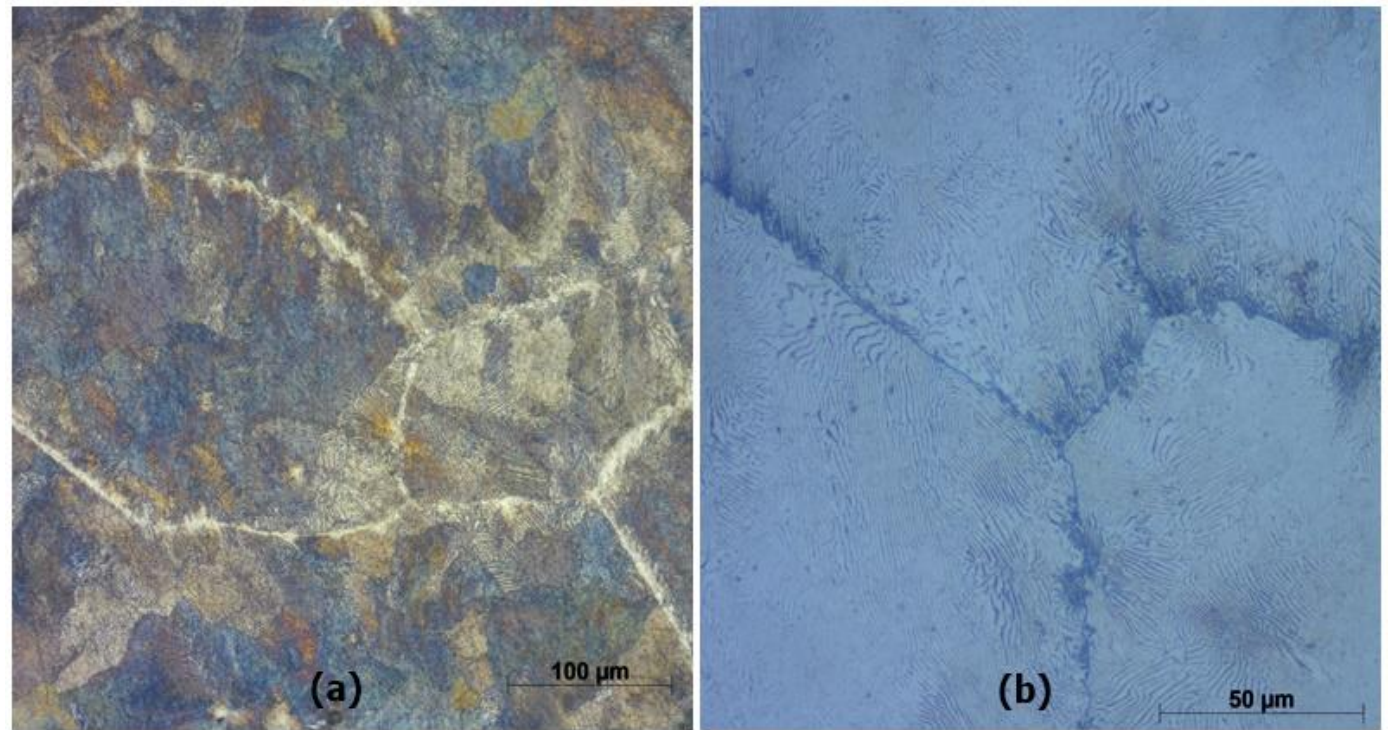

Fonte: os autores

A Figura 5 mostra a fotomicrografia do CP02 normalizado e atacado com Picrato de Sódio ataque que revela um contraste preto e branco, onde é possível evidenciar o formato dos grãos em uma estrutura refinada bem definida e homogênea. 


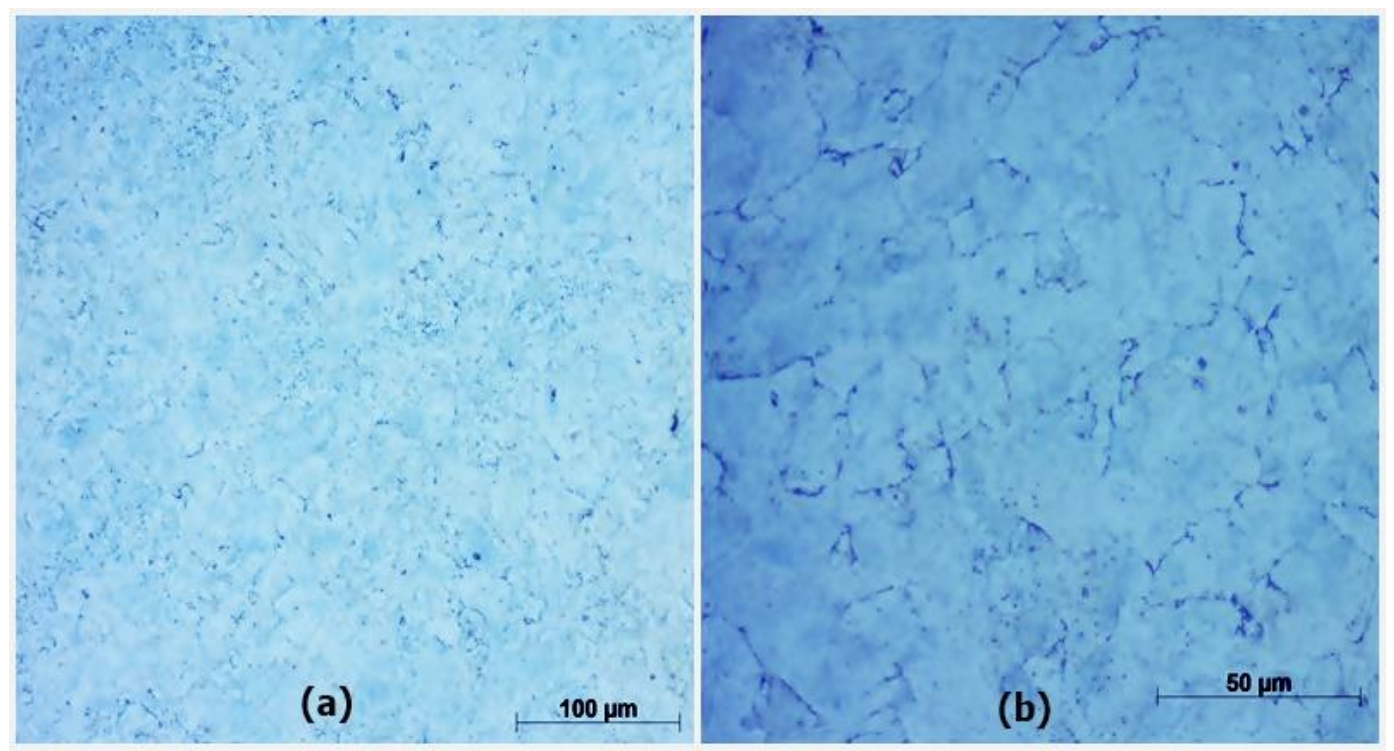

Fonte: os autores

Na Figura 6 observa-se o CP03 atacado com Nital 2\% destacando os contornos de grãos de cementita e a perlita presentes na matriz de martensita revenida.

Figura 6 - CP03 Temperado $\left(800^{\circ} \mathrm{C}\right)+\operatorname{Revenido~}\left(205^{\circ} \mathrm{C}\right)$. Ataque químico: Nital $2 \%$.

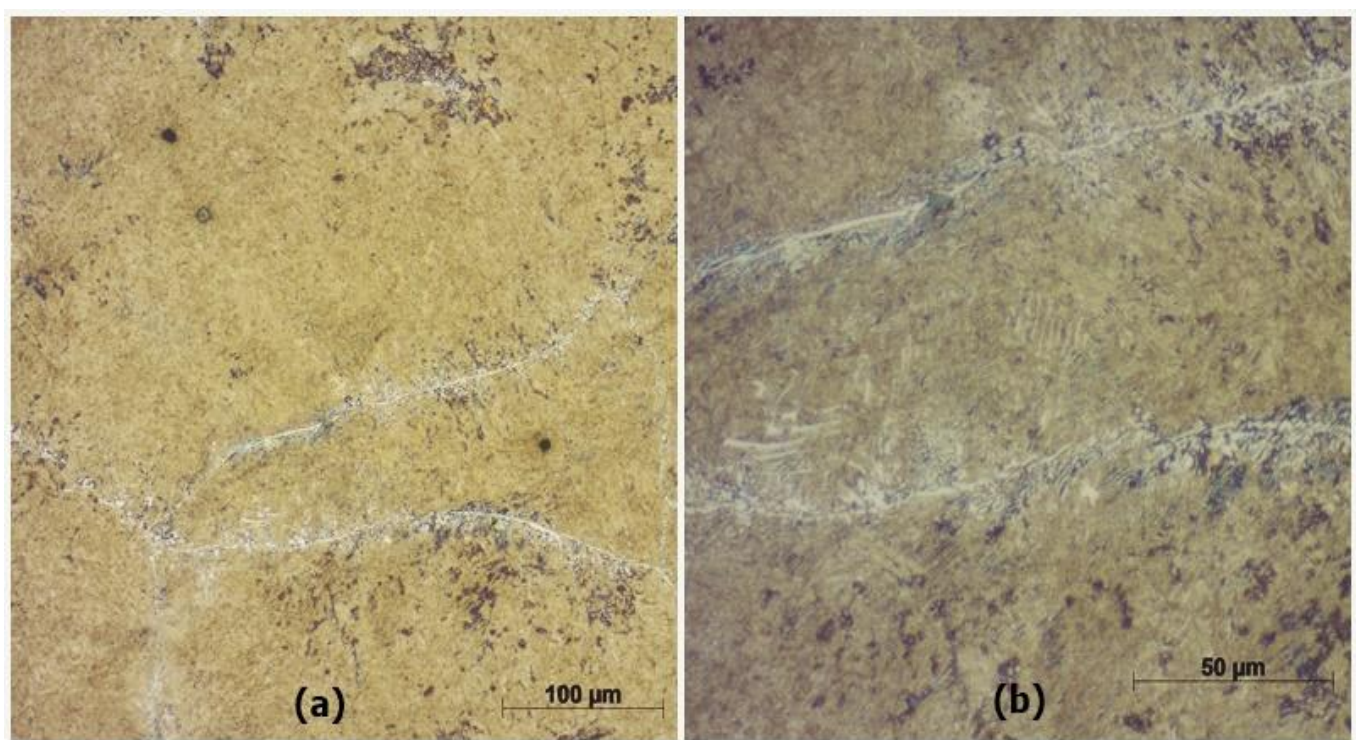

Fonte: os autores

O CP04 depois de temperado a $800^{\circ} \mathrm{C}$ e revenido a $420^{\circ} \mathrm{C}$ formou matriz martensita revenida e contorno de grãos com carbonetos, como mostra a Figura 7. 


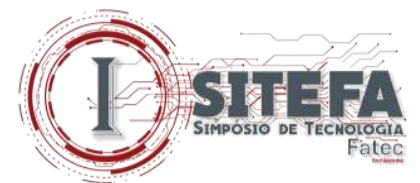

Figura 7 - CP4 Temperado $\left(800^{\circ} \mathrm{C}\right)+$ Revenido $\left(420^{\circ} \mathrm{C}\right)$. Ataque químico: Nital $2 \%$.

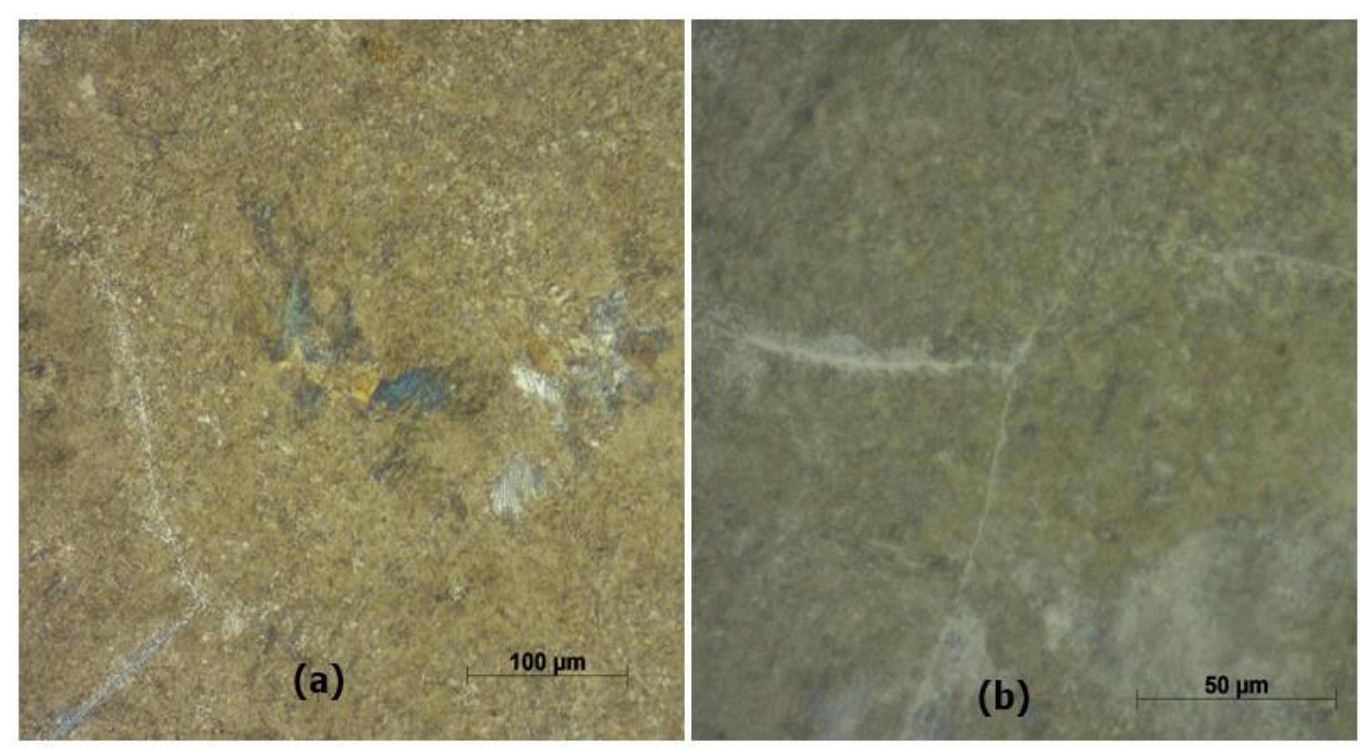

Fonte: os autores

Quando temperado a $900^{\circ} \mathrm{C}$ e revenido a $205^{\circ} \mathrm{C}$ formou-se matriz martensitica com austenita retida, observa-se na Figura 8.

Figura 8 - CP5 Temperado $\left(900^{\circ} \mathrm{C}\right)+\operatorname{Revenido~}\left(205^{\circ} \mathrm{C}\right)$. Ataque químico: Nital $2 \%$.

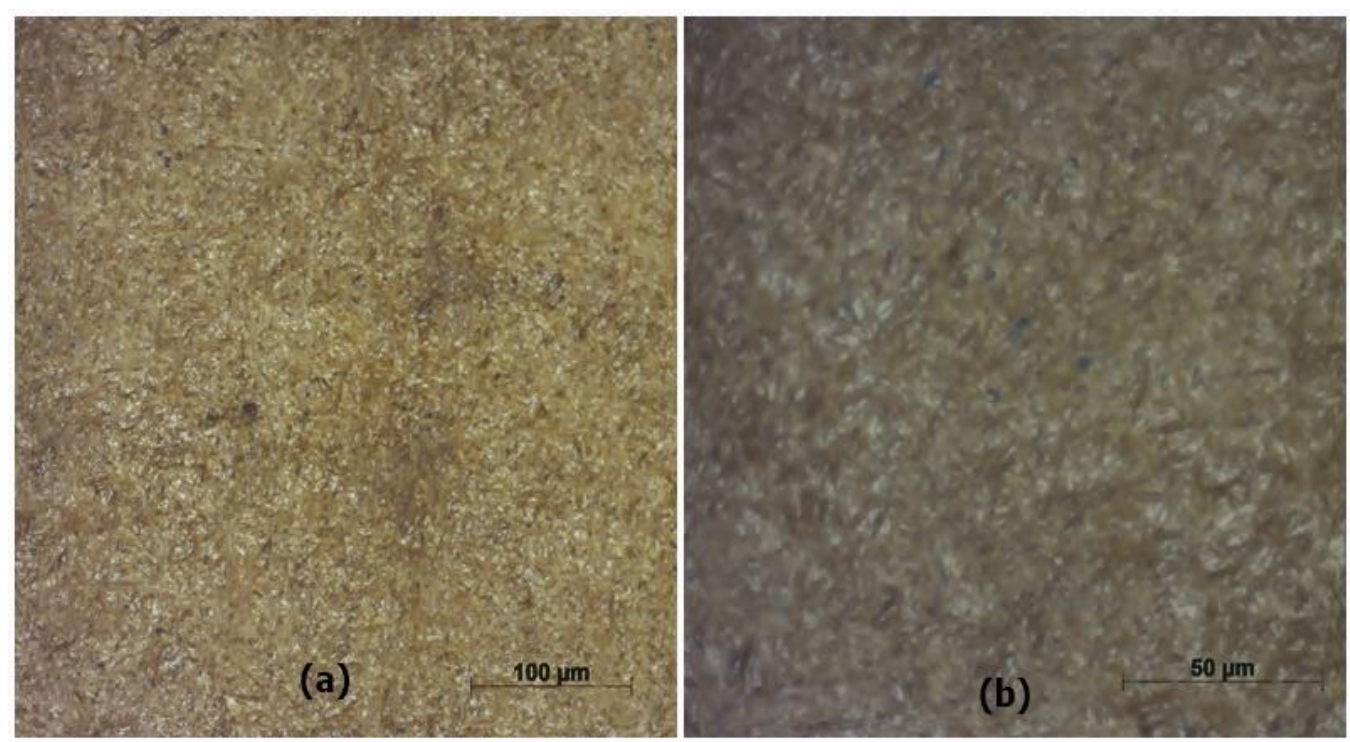

Fonte: os autores

A Figura 9 apresentou uma estrutura revelada composta de carbonetos (pontos esbranquiçados) na matriz de martensita revenida. 
Figura 9 - CP6 Temperado $\left(900^{\circ} \mathrm{C}\right)+$ Revenido $\left(420^{\circ} \mathrm{C}\right)$. Ataque químico: Nital $2 \%$.
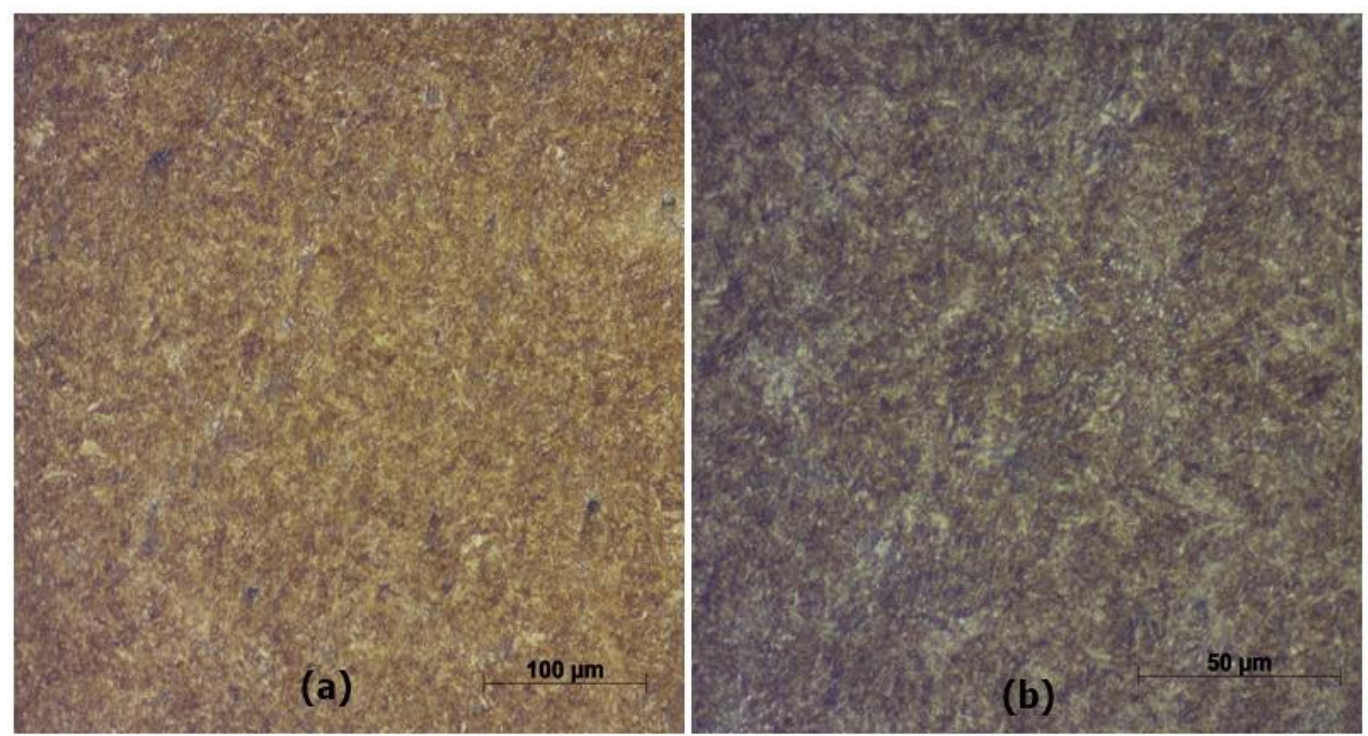

Fonte: os autores

\section{CONCLUSÃO}

Com base nos resultados obtidos durante a realização desta pesquisa conclui-se que:

- Quanto ao aço em estudo: O aço SAE 1095 se mostrou favorável aos tratamentos térmicos de têmpera obtendo dureza elevada entre 50 e $61 H R c$ tornando-o um aço frágil sendo necessário o revenimento.

- Quanto aos tratamentos térmicos: os tratamentos térmicos que melhor se sobressaíram na resistência ao desgaste abrasivo foram a normalização, a têmpera a $\left(800^{\circ} \mathrm{C}\right)+$ Revenido $\left(420^{\circ} \mathrm{C}\right)$ e a têmpera $\left(900^{\circ} \mathrm{C}\right)+$ Revenido $\left(420^{\circ} \mathrm{C}\right)$.

- E a microestrutura que melhor resistiu ao desgaste segundo os resultados obtidos foi a do CP06 sendo a matriz de martensita revenida composta de carbonetos.

Por fim concluímos que para a utilização deste aço para aplicações de desgaste, os tratamentos térmicos têm grande importância para alcançar seus objetivos de alta dureza combinados a tenacidade e microestrutura, fatores de extrema importância para que o aço tenha um bom desempenho. 


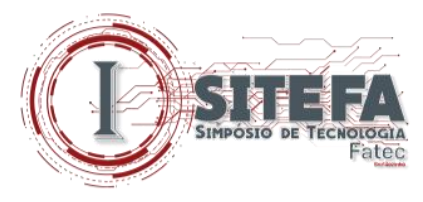

\section{REFERÊNCIAS}

ASTM G-65-04: Standard Test Method for Ranking Resistence of Materials to Sliding Wear Using Block-on-Ring Wear Test. 2010.

CASTRO, Cristóvão Américo Ferreira. Resistência ao Desgaste Abrasivo das Sapatas de Trator de Esteira Após Processos de Recuperação. 73 p. (PPG em Engenharia Mecânica e de Materiais) - Universidade de Tecnologia Federal do Paraná, Curitiba - PR, 2010.

CALLISTER, Jr. Ciência e Engenharia dos Materiais uma introdução. 8. ed. Rio de Janeiro: LTC, 2015, p. 291-325.

CHIAVERINI, V. Tratamentos térmicos das ligas metálicas. 5. ed. São Paulo: ABM, 2003. 171. Aços e ferros fundidos. 7. ed. revisada e ampliada: São Paulo: ABM, 2008, p. 159-

FARAH, Alessandro Fraga. Desenvolvimento de uma Liga de Ferro Fundido Branco com Alto Cromo com Nióbio, Tratada Termicamente para a Resistência ao Desgaste Abrasivo. 112p. (Dissertação de Mestrado) - Escola de engenharia de São Carlos Universidade de São Paulo, São Carlos, 1997.

GREGOLIN, J.A.R. Desenvolvimento de Ligas Fe-C-Cr (Nb) Resistentes ao Desgaste. 241p. (Tese de Doutorado) - UNICAMP - Univ. Est. de Campinas, Campinas - SP, 1990.

MANUAL DE AÇOS GERDAU. 2017. Disponível em:

$<$ http://www.feis.unesp.br/Home/departamentos/engenhariamecanica/maprotec/catalogo_acos _gerdau.pdf>.Acesso em: 10 de jul. 2017.

MARQUES, P. V.; MODENESI, P. J.; BRACARENSE, A. Q. Soldagem: Fundamentos e Tecnologia. 3. ed. Belo Horizonte: UFMG, v. Único, 2011. 